\title{
Serum lipid and apolipoprotein distributions in Hong Kong Chinese
}

Ping-Ching Fong, Sidney Chi-Fai Tam, Yau-Ting Tai, Chu-Pak Lau, Joseph Lee, Yuk-Yu Sha

\begin{abstract}
Study objective-The aim was to describe the distribution of lipids and apolipoproteins in the Chinese population in Hong Kong.

Design - This was a prospective, cross sectional, population based survey.

Settings - The study was conducted in a single, self referred, out patient screening centre.

Participants - Altogether 825 Chinese adults aged $\geqslant 20$ years were screened. One hundred subjects who had previously had lipid measurement and 29 who were taking lipid modifying drugs were excluded but 289 men and 407 women remained for further analysis.
\end{abstract}

Main results - Age standardised mean (SEM) lipids concentrations for Hong Kong Chinese were total cholesterol: men, $5.48(0.05) \mathrm{mmol} / 1$ and women, 5.46 (0.06) mmol/1; triglycerides: men, 1.22 (1.03) $\mathrm{mmol} / \mathrm{l}$ and women, 1.00 (1.03) mmol/1; high density lipoprotein (HDL) cholesterol: men, $1.25(0.02) \mathrm{mmol} / 1$ and women, $1.42(0.02) \mathrm{mmol} / \mathrm{l}$; low density lipoprotein (LDL) cholesterol: men, 3.56 $(0.05) \mathrm{mmol} / 1$ and women, $3.50(0.06)$ mmol/1; apolipoprotein A-I (apo A-I): men, $1.34(0.01) \mathrm{g} / 1$ and women, $1.46(0.01)$ $\mathrm{g} / \mathrm{l}$; and apolipoprotein $B$ (apo $B$ ): men, $1.15(0.02) \mathrm{g} / 1$ and women, $1.06(0.02) \mathrm{g} / 1$. The total to HDL cholesterol ratios were men, 4.62 (0.07) and women, $4.10(0.08)$; and apo $B$ to apo $A-I$ ratios (apo $B / A$ ) were men, $0.88(0.02)$ and women, 0.75 (0.02). While levels of total cholesterol, LDL cholesterol, apo $B$, triglycerides, total/HDL cholesterol, and apo $B / A$ were positively associated with age in both sexes and were higher in men before the age 50-59 years, they rose steeply thereafter in women to cross over the levels in men. In contrast, HDL cholesterol decreased with age while apo A-I remained constant, and both were consistently higher in women than in men in all age groups.

Conclusions - Hong Kong Chinese have attained lipid profiles similar to those in other developed western populations. Environmental factors seem influential in this regard. Faced with the increasing coronary mortality of recent years, there should be a major effort to reduce the cholesterol concentrations in this population.

( $\mathcal{F}$ Epidemiol Community Health 1994;48:356-361)
It is well recognised that both the incidence of coronary heart disease and serum cholesterol concentrations in various parts of China are relatively low when compared with those in western countries. ${ }^{1-3}$ Although the blood cholesterol concentration and coronary heart disease mortality increase as societies become more developed and urbanised, they remain lower than those in healthy whites. ${ }^{1}$ Hong Kong, a British colony but essentially a Chinese community, is a crossroads between the east and the west and is renowed for its enormous economic growth and the extent of urbanisation in recent decades. These developments have brought important changes to the people's lifestyle so that the traditional Chinese culture and dietary habits are being replaced by affluent western ones. More interestingly, there has been a concomitant rise in the coronary heart disease mortality and morbidity in recent years. ${ }^{4}$ While the cause for this is probably multifactorial, hyperlipidaemia is believed to play an important part. ${ }^{56}$ Thus, Hong Kong would have been an ideal model for studying the effect of such a degree of socioeconomic development on the lipid profiles of an ethnic group that has long been regarded as having low cholesterol concentrations. Until now, prospective data on lipid patterns in Hong Kong Chinese have been lacking and no reliable data on apolipoprotein profiles for Chinese have been reported so far. Moreover, to facilitate the implementation of relevant and effective public health strategies for reducing coronary heart disease in Hong Kong, information is needed on the lipid distributions of the population.

Bearing the above considerations in mind, a lipid screening programme was undertaken in 1991 to provide cross sectional data on the distribution of lipid and apolipoprotein concentrations in the Hong Kong Chinese, and to arouse public awareness of hyperlipidaemia. This study describes the serum lipid and apolipoprotein profiles and the effect of sex and age on these.

\section{Methods}

In a lipid screening programme organised by the Department of Medicine, University of Hong Kong in collaboration with the Department of Clinical Biochemistry, Queen Mary Hospital in 1991, 825 men and women were screened. The programme was operated on a self referral and free of charge basis and was publicised through health exhibitions, community centre visits, and free pamphlets. For organisational and administrative purposes, a 
single centre was established in the Sai Ying Pun Outpatient Clinic. The target population was ethnic Chinese aged 20 years or above. One hundred subjects with previous lipid measurement (with or without knowledge of the results) and 29 subjects who had been taking drugs known to affect serum lipid concentrations (such as lipid lowering agents, thiazides, $\beta$ blockers, and oral contraceptives) at the time of screening were excluded. Coronary heart disease, hypertension, and diabetes mellitus were not reasons for exclusion.

The demographic data, clinical history, and family history of the participants were obtained by filling in a questionnaire during the first visit, with guidance given if necessary. On the second visit, anthropometric measurements including body height and weight, waist and hip circumferences, and skin fold thicknesses at standard regions (biceps, triceps, subscapular, and supra-iliac) using a Lange caliper were performed by a trained research assistant or registered nurse. Sitting blood pressure in either arm was measured by a doctor using standard mercury sphygmomanometer after the participant had been at rest for at least five minutes. Finally, a $20 \mathrm{ml}$ sample of 12 hour overnight fasting venous blood was taken from each subject for blood biochemistry and lipid analysis.

All blood tests were performed in the laboratory of the Department of Clinical Biochemistry, Queen Mary Hospital - a major regional and university teaching hospital. Samples were centrifuged on the same day as venepuncture and the serum aliquots were stored at $-70^{\circ} \mathrm{C}$ until analysis. A batch of 80 serum samples were assayed in each session in order to minimise interassay variation. Levels of urea, creatinine, transaminases, alkaline phosphatase, glucose, total cholesterol, and triglycerides were determined using automated analysers (Hitachi 737 and 717 Analyzer, Boehringer Mannheim Ltd, Germany respectively). The apolipoprotein A-I (apo A-I) and apolipoprotein B (apo B) concentrations were determined on the Beckman Array Protein System (Beckman Instruments Inc, CA, USA) by rate nephelometry using calibrators as recommended in the standardisation programme by the International Federation of Clinical Chemistry and the World Health Organization (WHO). ${ }^{7-9}$ High density lipoprotein (HDL) cholesterol was measured as the cholesterol left in the serum after manganese phosphotungstic acid precipitation of the apo B-containing lipoprotein particles while low density lipoprotein (LDL) cholesterol ( $\mathrm{mmol} / \mathrm{l})$ was derived by the Friedewald formula ${ }^{10}:$ LDL cholesterol $=$ totalHDL cholesterol-(triglycerides/2.2).

Taking into consideration the opposing influences of total cholesterol or LDL cholesterol and HDL cholesterol on coronary heart disease risk, ratios such as total/HDL cholesterol, LDL/HDL cholesterol and HDL ratio have been shown to predict the coronary heart disease mortality better than cholesterol alone. ${ }^{112}$ Moreover, as quantitation of apo A-I and apo B gives better indices of $\mathrm{HDL}$ and LDL concentrations than does measurement of $\mathrm{HDL}$ and
LDL cholesterol, the ratio of apo B to apo A-I (apo B/A) is believed to provide an even better prediction of the coronary risk. ${ }^{313}$ In this report, we examined two such ratios: total/HDL cholesterol and Apo B/A.

Statistical analysis was performed using the computer statistical package of SPSS/PC+ V3.1 (SPSS Inc, Chicago). ${ }^{14}$ Descriptive statistics were calculated for the various lipid and apolipoprotein levels, stratified according to sex and age groups. Since the distribution of triglycerides in the study population was lognormal, triglyceride values were log-transformed in the statistical analysis so that the mean levels for this variable were actually geometric means and both the SD and SEM were approximate. To obtain a closer estimation of the population means, the overall means of the lipid and apolipoprotein levels for the sample were age standardised according to the age distributions among the population as reported in the 1991 population census. ${ }^{15}$ This was done by applying the weighting procedure $^{14}$ : the weight for each age group in either sex was obtained by dividing the percentage of the general population in that particular sex and age group by the corresponding percentage of the sample. This was to correct for the difference in the age distributions of the sample and the general population. Association between categorical variables was measured by the $\chi^{2}$ statistic whereas difference between dichotomy variables was tested by Student's $t$ test. Analysis of variance was used to assess the effect of age and sex on lipid variables. A two tailed $p$ value of less than 0.05 was considered statistically significant.

\section{Results}

There were 696 subjects (289 men and 407 women) eligible for the final analysis. The mean (SD) age was $45.4(14 \cdot 1)$ years, (range 20-91). Most demographic characteristics were similar in both sexes except that more men were employed in moderate and heavy labouring jobs $(24.8 \% \vee 20.1 \%, \mathrm{p}=0.0003)$ and more men smoked $(17 \%$ v $2.5 \%$, $\mathrm{p}<0.0001)$. The monthly household incomes (<\$5000, 14.7\%: \$5000-9999, 37.6\%: \$10 000-19 999, 30.4\%: $\$ 20000-50000$, $15 \cdot 4 \%$ : $>\$ 50000: 1.9 \%$ ) were similar to those reported in the 1991 population census. ${ }^{15} \mathrm{~A}$ past history of hypertension $(11 \cdot 2 \%)$, diabetes mellitus $(3.4 \%)$, coronary heart disease $(7 \cdot 9 \%)$, cerebrovascular accident $(1.4 \%)$, peripheral vascular disease $(1 \cdot 1 \%)$, renal diseases $(1.6 \%)$, gout $(6.3 \%)$, cirrhosis $(0.3 \%)$, hypothyroidism $(1.9 \%)$, and/or a family history of coronary heart disease $(11.9 \%)$, hypertension $(35.3 \%)$, diabetes $(20.7 \%)$, cerebrovascular accident $(13.5 \%)$, premature death under the age of $60(12.4 \%)$ and/or hyperlipidaemia $(8.4 \%)$ were noted among the subjects. Subjects were grouped according to alcohol consumption as non-drinkers $(62.5 \%)$, habitual drinkers $(3.4 \%)$, binge drinkers $(1.9 \%)$, social drinkers $(30.3 \%)$, and ex-drinkers $(1 \cdot 6 \%)$.

The age specific, mean concentrations of the 
various lipids, apolipoproteins, and risk ratios in relation to sex are given in Table 1. Despite similar mean total cholesterol concentrations in both sexes, their trends with age differed noticeably ( $p<0.001$ for age and interaction). The mean total cholesterol concentrations seemed to rise slowly from the youngest age group onwards in men whereas they remained lower in women before the age of 40-49 years, after which they increased steeply to become even higher than those in men. LDL cholesterol and apo $B$ values followed a similar trend $(p<0.001$ for age and interaction for LDL cholesterol; $\mathrm{p}<0.001$ for sex, age and interaction for apo B). In contrast, mean HDL cholesterol concentrations showed a significant steady decline with age in both sexes, with women having consistently higher levels in all age groups ( $p<0.01$ for age, $p<0.001$ for sex). Apo A-I concentrations, though also consistently higher in women in all age groups $(p<0.001)$, did not vary significantly with age. Triglyceride values tended to increase with age in both sexes $(p<0.001)$. However, the rise in men was gradual throughout while it was steep in women between the ages of 40-49 and 50-59 years. In addition, men always had higher triglyceride values than women in all age groups $(p<0.001)$ until 60 , at which age level began to fall. No significant correlation between the variation in lipid levels and alcohol consumption was found to account for the above observations.

About $43.1 \%$ of men and $46.8 \%$ of women in the community were estimated to have a total cholesterol concentration $<5.2 \mathrm{mmol} / 1$ while as many as $20 \cdot 7 \%$ of men and $21 \cdot 4 \%$ of women had a concentration $\geqslant 6.2 \mathrm{mmol} / \mathrm{l}$. Although the percentage of individuals with a total cholesterol $\geqslant 6.2 \mathrm{mmol} / 1$ increased with age, the percentage of individuals with borderline levels $(5 \cdot 2-6 \cdot 19 \mathrm{mmol} / \mathrm{l})$ was similar in every age group in both sexes. A low HDL cholesterol concentration $(<0.91 \mathrm{mmol} / \mathrm{l})$ was estimated to be present in $12.9 \%$ and $5.9 \%$ of men and women respectively as a whole, and the percentages always remained higher in

Table 1 Mean (SEM) serum lipid and apoliproprotein values in relation to sex and age

\begin{tabular}{|c|c|c|c|c|c|}
\hline & \multicolumn{5}{|c|}{ Age groups (y) } \\
\hline & $20-29$ & $30-39$ & $40-49$ & $50-59$ & $60+$ \\
\hline $\begin{array}{l}\text { Men } \\
\text { No of subjects } \\
\text { Total cholesterol (mmol/l) } \\
\text { Triglycerides }(\mathrm{mmol} / \mathrm{l}) \\
\text { HDL cholesterol }(\mathrm{mmol} / \mathrm{l}) \\
\text { LDL cholesterol }(\mathrm{mmol} / \mathrm{l}) \\
\text { Apolipoprotein A-I }(\mathrm{g} / \mathrm{l}) \\
\text { Apolipoprotein B }(\mathrm{g} / \mathrm{l}) \\
\text { Total/HDL cholesterol } \\
\text { Apolipoprotein B/A }\end{array}$ & $\begin{array}{l}44 \\
5.02(0.13) \\
0.87(1.06) \\
1.31(0.04) \\
3.28(0.13) \\
1.34(0.03) \\
0.97(0.04) \\
4.02(0.18) \\
0.75(0.04)\end{array}$ & $\begin{array}{l}81 \\
5.55(0.11) \\
1.22(1.07) \\
1.25(0.03) \\
3.65(0.10) \\
1.35(0.02) \\
1.19(0.03) \\
4.65(0.15) \\
0.91(0.03)\end{array}$ & $\begin{array}{l}58 \\
5.58(0.14) \\
1.46(1.09) \\
1.19(0.04) \\
3.56(0.13) \\
1.33(0.03) \\
1.17(0.04) \\
4.94(0.20) \\
0.90(0.03)\end{array}$ & $\begin{array}{l}59 \\
5.59(0.13) \\
1.54(1.08) \\
1.17(0.04) \\
3.57(0.12) \\
1.29(0.03) \\
1.20(0.04) \\
5.12(0.20) \\
0.95(0.04)\end{array}$ & $\begin{array}{l}47 \\
5.87(0.16) \\
1.37(1.10) \\
1.29(0.05) \\
3.86(0.12) \\
1.39(0.03) \\
1.29(0.05) \\
4.73(0.18) \\
0.95(0.04)\end{array}$ \\
\hline $\begin{array}{l}\text { Women } \\
\text { No of subjects } \\
\text { Total cholesterol }(\mathrm{mmol} / \mathrm{l}) \\
\text { Triglycerides }(\mathrm{mmol} / \mathrm{l}) \\
\text { HDL cholesterol }(\mathrm{mmol} / \mathrm{l}) \\
\text { LDL cholesterol }(\mathrm{mmol} / \mathrm{l}) \\
\text { ApolipoproteinA-I }(\mathrm{g} / \mathrm{l}) \\
\text { Apolipoprotein B }(\mathrm{g} / \mathrm{l}) \\
\text { Total/HDL cholesterol } \\
\text { Apolipoprotein B/A }\end{array}$ & $\begin{array}{l}63 \\
5.02(0.11) \\
0.74(1.06) \\
1.51(0.04) \\
3.13(0.11) \\
1.46(0.03) \\
0.88(0.03) \\
3.50(0.14) \\
0.62(0.03)\end{array}$ & $\begin{array}{l}96 \\
4.97(0.09) \\
0.88(1.06) \\
1.45(0.04) \\
3.03(0.09) \\
1.46(0.03) \\
0.91(0.03) \\
3.66(0.12) \\
0.65(0.03)\end{array}$ & $\begin{array}{l}93 \\
5.36(0.10) \\
0.99(1.04) \\
1.43(0.03) \\
3.44(0.09) \\
1.47(0.02) \\
1.05(0.03) \\
3.92(0.11) \\
0.73(0.03)\end{array}$ & $\begin{array}{l}70 \\
6.04(0.13) \\
1.40(1.05) \\
1.34(0.04) \\
3.99(0.13) \\
1.46(0.03) \\
1.27(0.04) \\
4.76(0.17) \\
0.90(0.04)\end{array}$ & $\begin{array}{l}85 \\
6.45(0.13) \\
1.47(1.06) \\
1.31(0.04) \\
4.37(0.12) \\
1.48(0.02) \\
1.40(0.04) \\
5.21(0.16) \\
0.97(0.03)\end{array}$ \\
\hline
\end{tabular}

men and tended to increase with age in both sexes.

As for the risk ratios, the total/HDL cholesterol concentration increased steadily with age in both sexes and was higher in men up to the age 50-59 years. Thereafter, the levels declined slightly in men while increasing steeply in women, so that the levels in the two sexes crossed over each other $(p<0.001$ for age and interaction). Apo B/A followed a similar trend as total/HDL cholesterol, except that values in men did not show a decline in the age group of $60+(p<0.001$ for sex, age, and interaction $)$.

\section{Discussion}

Chinese people have always been recognised as having lower serum cholesterol concentrations than whites..$^{1-3}$ Earlier studies in Shanghai in the 1950s showed that the mean serum total cholesterol concentration of healthy Chinese men above the age of 40 years was around $4 \cdot 1 \mathrm{mmol} / 1 .{ }^{16}$ Even in patients with myocardial infarction, the levels were still lower than those of healthy Americans. ${ }^{16}$ Another study of 2392 middle aged Chinese factory workers from urban Shanghai screened for serum total cholesterol in 1972-73 and in 1977-78 showed mean concentrations of $4.18 \mathrm{mmol} / 1$ and $4.19 \mathrm{mmol} / 1 \mathrm{respectively.}{ }^{2}$ In a survey of middle aged men and women in Beijing and Guangzhou in 1983-84, the total cholesterol concentrations were higher for urban workers than for rural farmers, with Guangzhou farmers having the lowest mean level of $4 \cdot 0$ $4.2 \mathrm{mmol} / \mathrm{l}$. Even in Beijing urban workers, the mean level was between $4 \cdot 7-4.9 \mathrm{mmol} / 1 .{ }^{1}$ A more recent study in 1986 involving 716 healthy Chinese controls in Tianjin showed a mean total cholesterol concentration of approximately $4.6 \mathrm{mmol} / 1$ in men and $4.8 \mathrm{mmol} / 1$ in women. ${ }^{3}$ This contrasts with western countries, where the average total cholesterol values for the United States and United Kingdom adult populations, for instance, are about $5.43 \mathrm{mmol} / 1$ and $5.8 \mathrm{mmol} / 1$ respectively. ${ }^{1718}$ The age standardised mean total cholesterol level of $5.47 \mathrm{mmol} / 1$ in the present study is much higher than values reported for the other Chinese populations but comparable with those in the western populations. Since most of the Hong Kong Chinese are descendants of the natives of the southern part of China or are actually immigrants from there, this suggests that the difference in the serum cholesterol concentrations between the Chinese in Hong Kong and in China is related more to environmental than genetic factors.

One important environmental factor among the others may be dietary cholesterol and fat intake. Results of dietary surveys in the PRCUSA cooperative study ${ }^{1}$ showed that the traditional Chinese diets had the common characteristics of a high carbohydrate content (mainly from starch) and a relatively low fat content, which made up $18 \%$ to $31 \%$ of the total daily caloric intake. Only $25 \%$ to $27 \%$ of the total fat was saturated fat. By contrast, according to data from the Lipid Research Clinic Study, the usual North American diet contains a considerably higher percentage $(40 \%)$ of energy from 
fat, a high proportion ( $37 \%$ ) of which is saturated fat. ${ }^{19}$ The mean daily intake of cholesterol was well below $300 \mathrm{mg}$ in most of the Chinese groups, while a distinctly higher intake of up to $500 \mathrm{mg}$ or more was found for American men. ${ }^{119}$ Although there is no documented, up to date data on the dietary pattern in Hong Kong Chinese, it is reckoned that the diet has changed into one containing the high fat and low fibre foods produced by modern food technology as the city becomes more affluent, and that the fat and cholesterol consumption is much higher than that in the traditional Chinese diet. This pattern of nutritional change is indeed found throughout the developing world. ${ }^{20}$ The observation that in recent years the annual consumption of meat and oil per capita in Hong Kong is increasing, while that of rice is decreasing provides further support to this hypothesis. ${ }^{21}$ Numerous studies on the effect of migration, including the well known Ni-Hon-San Study, also indicate that changes in the mode of life, particularly the shift to a richer diet as a result of migration from a less affluent part of the world to a more affluent western country, were associated with higher levels of serum cholesterol and higher coronary heart disease incidence and mortality, and that dietary lipids (cholesterol, saturated fat, polyunsaturated fat) played a key role in the short and long term determination of serum cholesterol levels in a population..$^{5622}$ Furthermore, the falling coronary heart disease mortality in the developed countries such as United States, Finland, Australia, and New Zealand has been associated with a reduction in blood cholesterol concentrations. ${ }^{2324}$ Thus, it is postulated that dietary changes may at least partially explain the finding of a relatively high mean cholesterol concentration in the study population and the rising coronary heart disease mortality in Hong Kong.

While data from the WHO programme of Multinational Monitoring of Trends in Cardiovascular Disease showed that the relative contribution to coronary risk made by cholesterol differs from population to population, ${ }^{11}$ consensus within Europe and the United States suggests that the "ideal" plasma cholesterol concentration is $<5.2 \mathrm{mmol} / 1{ }^{2526}$ As demonstrated by the Multiple Risk Factors Intervention Trial, the association between cholesterol levels and coronary risk is continuously graded and there is no cholesterol value at which risk is eliminated. ${ }^{27} \mathrm{~A}$ study in China also showed that even within the range of $3.8-4.7 \mathrm{mmol} / 1$ there was no good evidence of a threshold level of cholesterol below which a lower cholesterol concentration was no longer associated with a lower risk of coronary heart disease. ${ }^{2}$ These findings suggest that the "ideal" cholesterol levels should be even lower than $5.2 \mathrm{mmol} / \mathrm{l}$. If this is true, these cholesterol levels are well beyond ideal and serious attention to this problem is definitely required.

Our study points out the similarity of the epidemiology of serum lipids in our Chinese population and other white populations. ${ }^{202829}$ Although the menopausal status of the women was not checked in our study, it is believed that the hormonal changes may account for the accelerated rise in cholesterol concentrations in women after the menopause. One other noteworthy point is that our study found that HDL cholesterol concentrations fell slightly but significantly with age, whereas other studies did not show such a relationship. Although alcohol consumption was not shown to be an associated factor in this study, it may still be argued that the inadequacy of the power of the study design conceals any real relationship between them, or, some other factors such as ethnic difference may, in fact, be involved. This certainly needs further exploration.

Methodologically, there are certain limitations in our study. Firstly, the subjects were recruited on a self referral basis and those with higher lipid concentrations or positive family history might be more likely to come forward. However, we made every effort to exclude those who had had previous lipid checking and those who had been taking agents known to affect the lipid levels, and the prevalence of a positive family history of hyperlipidaemia was $8.4 \%$ only. Even after excluding this group of individuals, the results would not have been greatly altered. In fact, self selection bias is not totally excluded even by opportunistic case finding and random selection. ${ }^{20}$

Secondly, the age and sex distribution in the study population differed from that in the general population. This will not, however, affect the age specific means but rather the overall population means. The age standardised means were calculated in an attempt to take this sampling difference into account. While this method can, by no means, be regarded as a substitute for proper random sampling, it offers a better approximation of the population means.

Thirdly, 10 individuals had triglyceride levels higher than $5.6 \mathrm{mmol} / \mathrm{l}$, which rendered inaccurate the calculated LDL cholesterol. Nonetheless, this has little effect on the final results since their number is very small relative to the entire study population.

Fourthly, $124(17 \cdot 8 \%)$ individuals with a past history of coronary heart disease, diabetes mellitus or hypertension, were not excluded from the analysis. However, most of them were already being treated. Only $54(7.8 \%)$ of subjects had a diastolic blood pressure higher than $90 \mathrm{mmHg}$ and $19(2.7 \%)$ of subjects had fasting blood sugar more than $8 \mathrm{mmol} / \mathrm{l}$ at the time of screening. By using a $t$ test to compare the various age standardised lipid and apolipoprotein levels between the whole group and the selected past history free individuals, no significant difference was found (Table 2).

In addition, the findings on the epidemiology of the lipids were also consistent with what would have been expected from studies elsewhere. ${ }^{202829}$ In a research project carried out in 1983-85 concerning health risks, fitness, and quality of life in Hong Kong involving 1359 Chinese adults recruited by non-random cluster sampling in a low-cost housing estate and a privately owned one in Shatin area, fasting total cholesterol values were included as part of the assessment. Though their results (Table 3) can- 
Table 2 Age standardised lipoprotein values (mean (SD)) in the whole study group compared with values in subjects with no past medical history of coronary heart disease diabetes mellitus, and hypertension

\begin{tabular}{|c|c|c|c|c|c|c|}
\hline Group & $\begin{array}{l}\text { Total } \\
\text { cholesterol } \\
\text { (mmol/l) }\end{array}$ & $\begin{array}{l}\text { Triglycerides } \\
(\text { mmol } / \mathrm{l})\end{array}$ & $\begin{array}{l}\text { HDL } \\
\text { cholesterol } \\
\text { (mmol/l) }\end{array}$ & $\begin{array}{l}\text { LDL } \\
\text { cholesterol } \\
\text { (mmol/l) }\end{array}$ & $\begin{array}{l}\text { Apos } A-I \\
(\mathrm{~g} / \mathrm{l})\end{array}$ & $\begin{array}{l}A p o B \\
(g / l)\end{array}$ \\
\hline Total group & $\begin{array}{c}5 \cdot 47 \\
(1.08)\end{array}$ & $\begin{array}{c}1 \cdot 11 \\
(1 \cdot 78)\end{array}$ & $\begin{array}{c}1 \cdot 34 \\
(0 \cdot 34)\end{array}$ & $\begin{array}{l}3.53 \\
(1.0)\end{array}$ & $\begin{array}{c}1 \cdot 40 \\
(0 \cdot 24)\end{array}$ & $\begin{array}{c}1 \cdot 11 \\
(0 \cdot 34)\end{array}$ \\
\hline $\begin{array}{l}\text { No past } \\
\text { medical history }\end{array}$ & $\begin{array}{c}5 \cdot 45 \\
(1 \cdot 05)\end{array}$ & $\begin{array}{c}1 \cdot 06 \\
(1 \cdot 73)\end{array}$ & $\begin{array}{c}1 \cdot 36 \\
(0 \cdot 34)\end{array}$ & $\begin{array}{c}3.53 \\
(0.98)\end{array}$ & $\begin{array}{c}1.41 \\
(0 \cdot 23)\end{array}$ & $\begin{array}{c}1.09 \\
(0 \cdot 32)\end{array}$ \\
\hline
\end{tabular}

Table 3 Mean (SD) total cholesterol in an earlier study of 1359 Chinese adults $\geqslant 20$ years (46\% men, mean (SD) age 40.3 (14.6) years)

\begin{tabular}{|c|c|c|c|c|c|c|}
\hline \multirow{2}{*}{$\begin{array}{l}\text { Total } \\
\text { cholesterol } \\
\text { (mmol/l) }\end{array}$} & \multicolumn{6}{|c|}{ Age group (y) } \\
\hline & $20-29$ & $30-39$ & $40-49$ & $50-59$ & $60-69$ & $70+$ \\
\hline Men & $\begin{array}{c}4 \cdot 58 \\
(0 \cdot 98)\end{array}$ & $\begin{array}{c}4.93 \\
(0.98)\end{array}$ & $\begin{array}{c}5 \cdot 13 \\
(1 \cdot 03)\end{array}$ & $\begin{array}{c}5 \cdot 19 \\
(1 \cdot 25)\end{array}$ & $\begin{array}{c}5 \cdot 06 \\
(1 \cdot 16)\end{array}$ & $\begin{array}{c}4.38 \\
(0.72)\end{array}$ \\
\hline Women & $\begin{array}{c}4 \cdot 36 \\
(1 \cdot 07)\end{array}$ & $\begin{array}{c}4 \cdot 49 \\
(0 \cdot 98)\end{array}$ & $\begin{array}{c}4.69 \\
(0.91)\end{array}$ & $\begin{array}{c}5.51 \\
(1.31)\end{array}$ & $\begin{array}{c}5.67 \\
(1.38)\end{array}$ & $\begin{array}{r}5.29 \\
(1.39)\end{array}$ \\
\hline
\end{tabular}

Source: ref 30

not be directly compared with ours due to different sampling techniques and timing, similar cross over of the total cholesterol concentrations for the two sexes occurred between the age groups of $40-49$ and $50-59 .^{30}$

\section{Conclusion}

The study describes the distribution of lipids and apolipoproteins in Hong Kong Chinese. The lipid profiles obtained are comparable with those reported in other developed western populations and are by no means "ideal" as recommended by most of the lipid authorities. Environmental factors seem to play an important role in this regard. Faced with an increasing coronary mortality in recent years, there should be a major effort to reduce the cholesterol levels in this population.

We would like to thank Merck Sharp \& Dohme (Asia) Ltd for their generous support on the programme and Miss Bonnie Fong for her assistance in supervising the lipid and apolipoprotein measurements.

1 Tao S, Huang Z, Wu X, et al. CHD and its risk factors in the People's Republic of China. Int $\mathcal{F}$ Epidemiol 1989;18(Suppl 1):S159-63.

2 Chen Z, Peto R, Collins R, MacMahon S, Lu J, Li W. Serum cholesterol concentration and coronary heart disease in population with low cholesterol concentrations. BMF 1991;303:276-82.

3 Schwartzkopff W, Schleicher J, Pottins I, Yu S, Han C, Du D. Lipids, lipoproteins, apolipoproteins, and other risk factors in Chinese men and women with and without factors in Chinese men and women with and with

4 Annual Reports 1975-1989. Hong Kong: Medical and Health Department.

5 Kato H, Tillotson J, Nichaman MZ, Rhoads GG, Hamilton HB. Epidemiologic studies of coronary heart disease and stroke in Japanese men living in Japan, Hawaii and California-serum lipids and diet. Am $\mathcal{F}$ Epidemiol 1973;97:37285

6 Robertson TL, Kato H, Gordon T, et al. Epidemiologic studies of coronary heart disease and stroke in Japanese men living in Japan, Hawaii and California. Incidence of myocardial infarction and death from coronary heart disease. Am F Cardiol 1977;39:239-43.
7 Marcovina SM, Albers JJ. Standardization of the immunochemical determination of apolipoproteins A-I and B: A report on the international Federation of Clinical report on the international Federation of Clinical A-I and B measurements (basis for future consensus) A-I and B measurements (basis for future

8 Marcovina SM, Albers JJ. Apolipoprotein assays - standardization and quality control. Scand f Clin Lab Invest 1990;50(suppl 198):58-65.

9 Cooper GR, Henderson LM, Smith SJ, Hannon WH. Clinical applications and standardization of apolipoprotein measurements in the diagnostic workup of lipid disorders. Clin Chem 1991;37:619-20.

10 Friedewald WT, Levy RI, Frederickson DS. Estimation of the concentration of low-density lipoprotein cholesterol in plasma, without use of the preparative ultracentrifuge. Clin Chem 1972;18:499.

11 Simons LA. Interrelations of lipids and lipoproteins with coronary artery disease mortality in 19 countries. Am $\mathcal{J}$

12 Frick MH, Elo O, Haapa K, et al. Helsinki Heart Study primary prevention trial with gemfibrozil in middle-aged men with dyslipidemia. Safety of treatment, changes in risk factors, and incidence of coronary heart disease. $N$ Eng $\mathcal{f}$ Med 1987;317:1237-45.

13 Barbir M, Wile D, Trayner I, Aber VR, Thompson GR. High prevalence of hypertriglyceridaemia and apolipoprotein abnormalities in coronary artery disease. Br Heart $\mathcal{J}$ 1988;60:397-403.

14 SPSS/PC + V3.1 statistics guide. Chicago: SPSS Inc, 1988

5 Census and Statistics Department. Report on the population census 1991. Hong Kong: Census and Statistics Department.

16 Tung $\mathrm{CL}$, Wu $\mathrm{KH}$, Wang $\mathrm{CY}$. The relative incidence of atherosclerotic heart disease in East China and its relationship to cholesterol. Chin Med f 1958;77:596-602.

17 National Heart, Lung, and Blood Institute. National Cholesterol Education Program. Report of the expert panel on population strategies for blood cholesterol reduction: exepopulation strategies for blood cholesterol reduction: ex

18 Mann JI, Lewis B, Shepherd J, Winder AF, Fenster S, Rose L, Morgan B. Blood lipid concentrations and other cardiovascular risk factors: distribution, prevalence, and detecvascular risk factors: distribution, pre

19 The Lipid Research Clinics Population Studies Vol II. The prevalence study-nutrient intake. NIH publication No 822014. US Department of Health and Human Services, 1982.

20 Trowell HC, Burkitt DP, eds. Western diseases: their emergence and prevention. Cambridge, Mass: Harvard University Press, 1981.

21 Census and Annual Report 1975-1989. Census and Statistics Department, Hong Kong.

22 McMurry MP, Cerqueira MT, Connor SL, Connor WE. Changes in lipid and lipoprotein levels and body weight in Tarahumara indians after consumption of an affluent diet. N Eng $\mathcal{F}$ Med 1991;325:1704-8.

23 Stamler J. The marked decline in coronary heart disease mortality in the United States, 1968-1981; summary of findings and possible explanations. Cardiology 1985;72:1122.

24 Pyorala K, Salonen JT, Valkonen T. Trends in coronary heart disease mortality and morbidity and related factors in Finland. Cardiology 1985;72:35-51

25 The Expert Panel. Report of the National Cholesterol Education Program Expert Panel on detection, evaluation, and treatment of high blood cholesterol in adults. Arch Intern Med 1988;148:36-69.

26 Recognition and management of hyperlipidaemia in adults: a policy statement of the European Atherosclerosis Society. Eur Heart f 1988;9:571-600.

27 Stamler J, Wentworth D, Neaton JD for the MRFIT Research Group. Is relationship between serum cholesterol and risk of premature death from coronary heart disease continuous and graded?: Findings in 356222 primdisease continuous and graded?: Findings in 356222 primary screenees of the Multiple Risk Facto
(MRFIT). $A A M A$ 1986;256:2823-8.

28 Thorogood M, Carter R, Benfield L, MaPherson K, Mann JI. Plasma lipid lipoprotein cholesterol concentrations in people with different diets in Britain. BMF 1987;295:351-

29 Heiss G, Tamir I, Davis CE, Tyroler HA, Rifkind BM, Schonfeld G, Jacobs D, Frantz ID. Lipoprotein cholesterol distributions in selected North American populations: the Lipid Research Clinics Program Prevalence Study. Circulation 1980;61:302-15.

30 To CY, Donnan SPB. The Cooperative Cross-disciplinary Research Project on physical activities and quality of life in densely populated urban areas phase two study report (Part one). Health risks, fitness and puality of life in adults in (Part Kong. Hong Kong. The Chinese University in Hong Kong, School of Education and Department of Cong munity Medicine, 1988. 